\title{
Associations of sensory impairment and cognitive function in middle-aged and older Chinese population: The China Health and Retirement Longitudinal Study
}

\author{
Xiaohuan Zhao ${ }^{1,2,3 *}$, Yifan Zhou ${ }^{4 *}$, \\ Kunchen Wei ${ }^{5 *}$, Xinyue Bai ${ }^{1,2,3}$, \\ Jingfa Zhang ${ }^{1,2,3}$, Minwen Zhou ${ }^{1,2,3}$, \\ Xiaodong Sun ${ }^{1,2,3}$ \\ 'Department of Ophthalmology, Shanghai \\ General Hospital (Shanghai First People's \\ Hospital), Shanghai Jiao Tong University \\ School of Medicine, Shanghai, China \\ ${ }^{2}$ National Clinical Research Center for Eye \\ Diseases, Shanghai, China \\ ${ }^{3}$ Shanghai Key Laboratory of Fundus Diseases, \\ Shanghai, China \\ ${ }^{4}$ Putuo People's Hospital, Tongji University, \\ Shanghai 200060, China \\ ${ }^{5}$ Department of Plastic and Reconstructive \\ Surgery, Shanghai Ninth People's Hospital, \\ Shanghai Jiaotong University School of \\ Medicine, Shanghai, China \\ *Equal first authorship.
}

\begin{abstract}
Background Little is known about the associations between vision impairment, hearing impairment, and cognitive function. The aim of this study was to examine whether vision and hearing impairment were associated with a high risk for cognitive impairment in middle-aged and older Chinese adults.
\end{abstract}

Methods A total of 13914 Chinese adults from the China Health and Retirement Longitudinal Study (CHARLS) baseline were selected for analysis. Sensory impairment was assessed from a single self-report question, and we categorized sensory impairment into four groups: no sensory impairment, vision impairment, hearing impairment, and dual sensory impairment. Cognitive assessment covered memory, mental state, and cognition, and the data was obtained through a questionnaire.

Results Memory was negatively associated with hearing impairment $(\beta=-0.043,95 \%$ confidence interval $(\mathrm{CI})=-0.076,-0.043)$ and dual sensory impairment $(\beta=-0.033,95 \% \mathrm{CI}=-0.049,-0.017)$; mental status was negatively associated with vision impairment $(\beta=-0.034,95 \%$ $\mathrm{CI}=-0.049,-0.018)$, hearing impairment $(\beta=-0.070,95 \% \mathrm{CI}=-0.086$, $-0.055)$, and dual sensory impairment $(\beta=-0.054,95 \% \mathrm{CI}=-0.070$, $-0.039)$; and cognition was negatively associated with vision impairment $(\beta=-0.028,95 \% \mathrm{CI}=-0.044,-0.013)$, hearing impairment $(\beta=-0.074$, $95 \% \mathrm{CI}=-0.090,-0.059)$, and dual sensory impairment $(\beta=-0.052,95 \%$ $\mathrm{CI}=-0.067,-0.036)$, even after adjusting for demographics, social economic factors, and lifestyle behavior.

Conclusions Vision and hearing impairment are negatively associated with memory, mental status, and cognition for middle-aged and elderly Chinese adults. There were stronger negative associations between sensory impairment and cognitive-related indicators in the elderly compared to the middle-aged.

Cognitive impairment has been defined as a decline in the ability to remember, learn new things, and concentrate, which affects a person's daily life [1]. It is estimated that by 2050, China's dementia population will reach 10 million, which will create an overwhelming burden for individuals, families, and health care systems $[2,3]$. Thus, understanding the relevant factors of cognitive impairment is necessary to ameliorate cognitive impairment and prevent further loss. 
Recent evidence has demonstrated that sensory impairment, including hearing or vision impairment, is associated with a higher risk of cognitive impairment. About $94 \%$ of the elderly with cognitive impairment have hearing loss [4], and about $32.5 \%$ of dementia patients have vision loss [5]. Previous studies have found that listeners with hearing loss showed lower accuracy, increased reaction times, and reduced sensitivity compared to normal hearing listeners in vocal emotion recognition [6]. In a longitudinal study, sensorineural impairment in vision was associated with the incidence of cognitive impairment in middle-aged adults [7]. According to the baseline examination of the Beaver Dam Offspring Study, hearing and visual impairment were associated with poorer performance in cognitive functions independent of the other sensory impairments and factors associated with cognition in middle-aged adults [8]. Furthermore, visual function and symptoms have been identified as predictors of dementia and outcomes in Parkinson disease $[9,10]$. Moreover, dual sensory impairment refers to the simultaneous presence of visual impairment and hearing impairment, and its incidence is as high as $11 \%$ in adults over 80 years old [11]. Among black and white older adults, the risk of developing dementia increased in a dose-response way with increasing number of sensory impairments [12]. A long-term prospective study based on the data from the Health and Retirement Study (HRS) showed that individuals with combined hearing and visual impairments have a 38\% higher risk of incident possible CIND than individuals with no sensory impairment [13]. Recent studies have shown that elderly people with sensory and cognitive impairments, as a particularly common and vulnerable population, are at increased risk of hospitalization and lead to higher health care expenditures [14]. To explore the complex relationship between sensory impairment and cognitive impairment is of great significance to better formulate medical economic policies and help reduce the burden of social pension all over the world.

Few studies have focused on the role of sensory impairment in cognitive decline among people over 45 years old throughout China. Most previous studies have shown the relationship between a single sensory impairment and cognitive function impairment regardless of possible impairments in the other sensory systems. However, the China Health and Retirement Longitudinal Study (CHARLS) baseline data set reported information from Chinese people with or without hearing impairment, vision impairment, or dual sensory impairment. The purpose of this study was to verify if hearing impairment and vision impairment are independently associated with cognitive impairment, including the impairment of memory, mental status, and cognitive function, in middle-aged and elderly people in China.

\section{METHODS}

\section{Study population}

The data for this study was derived from the CHARLS baseline data set, which was run by the National School for Development at Peking University (http://charls.pku.edu.cn). The CHARLS study aims to establish a high-quality open database that includes information from a wide range of socioeconomic conditions and personal health conditions to facilitate research on the middle-aged and elderly. The participants include members aged 45 years and older from randomly selected households in 150 counties or districts and 450 villages or urban areas distributed across 28 provinces, generally representing the middle-aged and elderly people in China. The national baseline survey for CHARLS was conducted between June 2011 and March 2012 and included 17708 respondents [15].

\section{Assessment of sensory impairment}

Sensory impairment was assessed by asking, "Do you have vision or/and hearing problems?" We categorized sensory impairment into four groups: no sensory impairment, vision impairment, hearing impairment, and dual sensory impairment, comprising vision and hearing impairment.

\section{Assessment of cognition}

Based on the American Health and Retirement Study, CHARLS employed items from the Telephone Interview of Cognitive Status (TICS) battery [16]. Two factors were included to measure cognitive function: memory and mental status. Memory was evaluated by immediate and delayed word recall. The subjects heard 10 unrelated Chinese words and were asked to recall them immediately (immediate word recall) and then four minutes later (delayed word recall). Mental status was assessed from three dimensions, including orientation, visuoconstruction, and mathematical performance. Orientation measures included naming today's date (day, month, and year), the day of the week, and the season. Visuoconstruction asked participants to repaint 
pictures presented to them. Additionally, serial subtraction of 7 from 100 (up to five times) was used to evaluate the subjects' mathematical performance. The above items were combined to evaluate the participants' cognitive function [17].

\section{Assessment of covariates}

Using the CHARLS questionnaire, we obtained information on some covariates in the present study, including age, sex, residence (urban or rural), education (primary or below, middle school, high school, or college or above), smoking status, drinking status (none, drink but less than once a month, or drink more than once a month), hypertension, diabetes, and dyslipidemia. Age was categorized as middle aged ( $\geq 45$ and $<60$ years) and elderly ( $\geq 60$ years). Hypertension was defined as mean systolic blood pressure $\geq 140 \mathrm{~mm} \mathrm{Hg}$ and/or mean diastolic blood pressure $\geq 90 \mathrm{~mm} \mathrm{Hg}$, and/or self-reported use of antihypertensive medicine within two weeks according to the 2010 Chinese guidelines for hypertension [18]. The definition of diabetes comprised a subject having fasting blood glucose levels $\geq 7.0 \mathrm{mmol} / \mathrm{L}$ or currently taking hypoglycemic medicine. The diagnosis of dyslipidemia refers to total cholesterol $\geq 240 \mathrm{mg} / \mathrm{dl}$, high-density lipoprotein cholesterol $<40 \mathrm{mg} / \mathrm{dl}$, low-density lipoprotein cholesterol $>160 \mathrm{mg} / \mathrm{dl}$, or triglycerides $\geq 200 \mathrm{mg} / \mathrm{dl}$ based on the 2016 Chinese guidelines for dyslipidemia in adults [19].

\section{Statistical analysis}

Continuous variables were presented as mean \pm standard deviation (SD), whereas categorical variables were presented as numbers and percentages. For a comparison among the different groups, one-way analysis of variance (ANOVA) or the Kruskal-Wallis test for continuous variables and the $\chi^{2}$ test for categorical variables were used to evaluate differences. Pearson correlation analysis was performed to evaluate the relationships between the covariates and cognition. To evaluate the relationship between sensory impairment and cognition, weighted multiple linear regression was used to fit three sets of models we built. Model 1 adjusted for age and sex. Model 2 adjusted for the covariates in model 1 plus marital status, residence, education, smoking status, and drinking status. Model 3 adjusted for the covariates in model 2 plus hypertension, dyslipidemia, and diabetes. Because CHARLS has a complex sampling design, sampling weights were considered in the regression analyses. To examine the robustness of the results, a sensitivity analysis was conducted according to age.

\section{RESULTS}

\section{Characteristics of samples}

Among the included participants, subjects aged under 45 years or with incomplete demographic or health status data were excluded. Thus, 13914 individuals were included in the final analysis, including 6692 males (48.1\%) and 7222 (51.9\%) females. The baseline demographic characteristics of samples according to sensory impairment status are summarized in Table 1 . Those who had sensory impairment were older, more likely to be rural, and possessed a lower level of education. Moreover, people with sensory impairments were more likely to be smokers and have hypertension and diabetes. Interestingly, sensory impairments were accompanied by decline in the function of memory, cognition, and mental status.

\section{The correlation between cognition and covariates}

The correlations between cognition and the covariates were analyzed by Pearson correlation analysis and are displayed by correlation coefficients and their $P$-values in Table 2 . Significant correlations were found between cognition and independent variables, such as age, residence, education, and sensory impairment. Significant and negative correlations were found between age and memory $(r=-0.222, P<0.001)$, mental status $(r=-0.196$, $P<0.001)$, and cognition $(r=-0.231, P<0.001)$, which implies that memory, mental status, and cognitive function decrease with the increase of age. The associations between the level of education and memory $(r=0.246$, $P<0.001)$, mental status $(r=0.307, P<0.001)$, and cognition $(r=0.319, P<0.001)$ were significant and positive with the correlation coefficient estimated as $0.246(P<0.001), 0.307(P<0.001)$, and $0.319(P<0.001)$, respectively. Similar significant tendencies were found for the correlations between residence and memory $(r=0.119, P<0.001)$, mental status $(r=0.190, P<0.001)$, and cognition $(r=0.183, P<0.001)$. Significant and negative correlations were also found between sensory impairment and memory $(r=-0.131, P<0.001)$, mental status $(r=-0.156, P<0.001)$, and cognition $(r=-0.164, P<0.001)$, which indicates that memory, mental status, and cognitive function decreased with the increase of sensory impairment. 
Table 1. Demographic characteristics of middle-aged and elderly Chinese with and without dual sensory impairment

\begin{tabular}{|c|c|c|c|c|c|}
\hline VARIABLES & $\begin{array}{l}\text { NO SENSORY } \\
\text { IMPAIRMENT }\end{array}$ & $\begin{array}{c}\text { VISION } \\
\text { IMPAIRMENT }\end{array}$ & $\begin{array}{l}\text { HEARING } \\
\text { IMPAIRMENT }\end{array}$ & $\begin{array}{l}\text { DUAL SENSORY } \\
\text { IMPAIRMENT }\end{array}$ & P-VAlue \\
\hline No. subjects (\%) & $12143(87.3)$ & $553(4.0)$ & $924(6.6)$ & $294(2.1)$ & \\
\hline Age, year & $58.12 \pm 9.60$ & $62.66 \pm 10.12$ & $66.45 \pm 11.29$ & $67.70 \pm 11.40$ & $<0.001$ \\
\hline Sex, n (\%): & & & & & 0.005 \\
\hline Male & $5826(48.0)$ & $243(43.9)$ & $488(52.8)$ & $135(45.9)$ & \\
\hline Female & $6317(52.0)$ & $310(56.1)$ & $436(47.2)$ & $159(54.1)$ & \\
\hline Residence, n (\%): & & & & & $<0.001$ \\
\hline Urban & $5110(42.1)$ & $169(30.6)$ & $295(31.9)$ & $79(26.9)$ & \\
\hline Rural & $7033(57.9)$ & $384(69.4)$ & $629(68.1)$ & $215(73.1)$ & \\
\hline Education, $\mathrm{n}(\%)$ : & & & & & $<0.001$ \\
\hline Primary or below & $7727(63.6)$ & $456(82.5)$ & $761(82.4)$ & $252(85.7)$ & \\
\hline Middle school & $2708(22.3)$ & $69(12.5)$ & $97(10.5)$ & $27(9.2)$ & \\
\hline High school & $1363(11.2)$ & $24(4.3)$ & $52(5.6)$ & $10(3.4)$ & \\
\hline College or above & $345(2.9)$ & $4(0.7)$ & $14(1.5)$ & $5(1.7)$ & \\
\hline Smoking status, n (\%): & & & & & 0.001 \\
\hline Yes & $4734(39.0)$ & $220(39.8)$ & $424(45.9)$ & $122(41.5)$ & \\
\hline No & $7409(61.0)$ & $333(60.2)$ & $500(54.1)$ & $172(58.5)$ & \\
\hline Drinking status, $\mathbf{n}(\%)$ : & & & & & 0.246 \\
\hline Drink more than once a month & $3079(25.3)$ & $128(23.1)$ & $213(23.0)$ & $69(23.5)$ & \\
\hline Drink but less than once a month & $979(8.1)$ & $38(6.9)$ & $75(8.1)$ & $17(5.8)$ & \\
\hline None & $8085(66.6)$ & $387(70.0)$ & $636(68.9)$ & $208(70.7)$ & \\
\hline Hypertension, $\mathrm{n}(\%)$ : & & & & & $<0.001$ \\
\hline Yes & $2879(23.7)$ & $168(30.4)$ & $257(27.8)$ & $96(32.7)$ & \\
\hline No & $9264(76.3)$ & $385(69.6)$ & $667(72.2)$ & $198(67.3)$ & \\
\hline Diabetes, n (\%): & & & & & $<0.001$ \\
\hline Yes & $664(5.5)$ & $59(10.7)$ & $56(6.1)$ & $26(8.9)$ & \\
\hline No & $11479(94.5)$ & $494(89.3)$ & $868(93.9)$ & $268(91.1)$ & \\
\hline Dyslipidemia, n (\%): & & & & & 0.727 \\
\hline Yes & $1097(9.0)$ & $50(9.0)$ & $87(9.4)$ & $32(10.9)$ & \\
\hline No & $11046(91.0)$ & $503(91.0)$ & $837(90.6)$ & $262(89.1)$ & \\
\hline Memory & $3.41 \pm 2.22$ & $2.94 \pm 1.97$ & $2.42 \pm 2.12$ & $2.36 \pm 1.96$ & $<0.001$ \\
\hline Mental status & $6.74 \pm 3.60$ & $5.46 \pm 3.43$ & $4.99 \pm 3.72$ & $4.44 \pm 3.61$ & $<0.001$ \\
\hline Cognition & $10.15 \pm 5.17$ & $8.41 \pm 4.73$ & $7.41 \pm 5.32$ & $6.81 \pm 5.01$ & $<0.001$ \\
\hline
\end{tabular}

Table 2. Correlation between covariates and cognition

\begin{tabular}{lcccccc} 
VARiables & \multicolumn{2}{c}{ Memory } & \multicolumn{2}{c}{ Mental Status } & \multicolumn{2}{c}{ Cognition } \\
& $\mathbf{r}$ & $\boldsymbol{P}$-value & $\mathbf{r}$ & $\boldsymbol{P}$-value & $\mathbf{r}$ & $\boldsymbol{P}$-value \\
Age & -0.222 & $<0.001$ & -0.196 & $<0.001$ & -0.231 & $<0.001$ \\
\hline Sex & 0.016 & 0.055 & 0.156 & $<0.001$ & 0.115 & $<0.001$ \\
\hline Residence & 0.119 & $<0.001$ & 0.190 & $<0.001$ & 0.183 & $<0.001$ \\
\hline Education & 0.246 & $<0.001$ & 0.307 & $<0.001$ & 0.319 & $<0.001$ \\
\hline Smoking status & 0.011 & 0.212 & 0.089 & $<0.001$ & 0.067 & $<0.001$ \\
\hline Drinking status & -0.029 & 0.001 & -0.078 & $<0.001$ & -0.067 & $<0.001$ \\
\hline Hypertension & -0.017 & 0.047 & -0.012 & 0.141 & -0.016 & $<0.001$ \\
\hline Diabetes & 0.023 & 0.006 & 0.026 & 0.002 & 0.028 & 0.001 \\
\hline Dyslipidemia & 0.065 & $<0.001$ & 0.062 & $<0.001$ & 0.071 & $<0.001$ \\
\hline Sensory impairment & -0.131 & $<0.001$ & -0.156 & $<0.001$ & -0.164 & $<0.001$ \\
\hline
\end{tabular}

\section{Associations between sensory impairment and cognitive function}

To further clarify the association between sensory impairment and cognitive function, we reanalyzed their relevance by controlling for the covariates in the base model (Table 3). Memory was negatively associated with vision impairment $(\beta=-0.023,95 \% \mathrm{CI}=-0.039,-0.007)$, hearing impairment $(\beta=-0.071,95 \% \mathrm{CI}=-0.087$, $-0.054)$, and dual sensory impairment $(\beta=-0.040,95 \% \mathrm{CI}=-0.057,-0.054)$ after adjusting for age and sex. Surprisingly, memory was still negatively associated with hearing impairment $(\beta=-0.059,95 \% \mathrm{CI}=-0.075,-0.043)$ 
Table 3. Associations between sensory impairment and cognitive function in middle-aged and elderly Chinese*

\begin{tabular}{lclll} 
VARIABLES & $\begin{array}{l}\text { No sensory } \\
\text { impairment }\end{array}$ & Vision impairment & Hearing impairment & Dual sensory impairment \\
Memory: & & & & \\
\hline Model 1 & Ref & $-0.023(-0.039,-0.007)$ & $-0.071(-0.087,-0.054)$ & $-0.040(-0.057,-0.054)$ \\
\hline Model 2 & Ref & $-0.011(-0.027,0.005)$ & $-0.059(-0.075,-0.043)$ & $-0.032(-0.048,-0.016)$ \\
\hline Model 3 & Ref & $-0.011(-0.027,0.005)$ & $-0.043(-0.076,-0.043)$ & $-0.033(-0.049,-0.017)$ \\
\hline Mental status: & & & & \\
\hline Model 1 & Ref & $-0.051(-0.067,-0.034)$ & $-0.087(-0.104,-0.071)$ & $-0.066(-0.082,-0.050)$ \\
\hline Model 2 & Ref & $-0.033(-0.048,-0.018)$ & $-0.070(-0.086,-0.054)$ & $-0.054(-0.069,-0.038)$ \\
\hline Model 3 & Ref & $-0.034(-0.049,-0.018)$ & $-0.070(-0.086,-0.055)$ & $-0.054(-0.070,-0.039)$ \\
\hline Cognition: & & & & \\
\hline Model 1 & Ref & $-0.045(-0.061,-0.029)$ & $-0.091(-0.107,-0.075)$ & $-0.063(-0.079,-0.047)$ \\
\hline Model 2 & Ref & $-0.028(-0.043,-0.012)$ & $-0.074(-0.090,-0.058)$ & $-0.051(-0.067,-0.036)$ \\
\hline Model 3 & Ref & $-0.028(-0.044,-0.013)$ & $-0.074(-0.090,-0.059)$ & $-0.052(-0.067,-0.036)$ \\
\hline
\end{tabular}

*Model 1 adjusted for age and sex. Model 2 adjusted for covariates in model 1 plus marital status, residence, education, smoking status, and drinking status. Model 3 adjusted for covariates in model 2 plus, hypertension, dyslipidemia, and diabetes.

and dual sensory impairment ( $\beta=-0.032,95 \% \mathrm{CI}=-0.048,-0.016)$ after further controlling for marital status, residence, education, smoking status, and drinking status. After further controlling for hypertension, dyslipidemia, and diabetes, memory still had significant negative associations with hearing impairment $(\beta=-0.043$, $95 \% \mathrm{CI}=-0.076,-0.043)$ and dual sensory impairment $(\beta=-0.033,95 \% \mathrm{CI}=-0.049,-0.017)$.

Furthermore, mental status was negatively associated with vision impairment $(\beta=-0.051,95 \% \mathrm{CI}=-0.067$, -0.034), hearing impairment $(\beta=-0.087,95 \% \mathrm{CI}=-0.104,-0.071)$, and dual sensory impairment $(\beta=-0.066$, $95 \% \mathrm{CI}=-0.082,-0.050)$ after adjusting for age and sex. When additionally adjusting for social economic factors and lifestyle behavior, mental status was still negatively associated with vision impairment $(\beta=-0.033$, $95 \% \mathrm{CI}=-0.048,-0.018)$, hearing impairment $(\beta=-0.070,95 \% \mathrm{CI}=-0.086,-0.054)$, and dual sensory impairment $(\beta=-0.054,95 \% \mathrm{CI}=-0.069,-0.038)$. Consistently, mental status had negative associations with vision impairment $(\beta=-0.034,95 \% \mathrm{CI}=-0.049,-0.018)$, hearing impairment $(\beta=-0.070,95 \% \mathrm{CI}=-0.086,-0.055)$, and dual sensory impairment $(\beta=-0.054,95 \% \mathrm{CI}=-0.070,-0.039)$ when controlling for hypertension, dyslipidemia, and diabetes.

Reviewing cognitive function, cognition was associated with lower visual impairment, lower hearing impairment, and lower dual sensory impairment regardless of adjusting the covariates. Cognition was negatively associated with vision impairment ( $\beta=-0.045,95 \% \mathrm{CI}=-0.061,-0.029)$, hearing impairment $(\beta=-0.091,95 \%$ $C I=-0.107,-0.075)$, and dual sensory impairment $(\beta=-0.063,95 \% \mathrm{CI}=-0.079,-0.047)$ after adjusting for age and sex. Significant negative relationships were observed between cognition and vision impairment $(\beta=-0.028$, $95 \% \mathrm{CI}=-0.043,-0.012)$, hearing impairment $(\beta=-0.074,95 \% \mathrm{CI}=-0.090,-0.058)$, and dual sensory impairment $(\beta=-0.051,95 \% \mathrm{CI}=-0.067,-0.036)$ after adjusting for social economic factors and lifestyle behavior. Even if metabolism-related factors were further adjusted, there were still negative associations between cognition and vision impairment ( $\beta=-0.028,95 \% \mathrm{CI}=-0.044,-0.013)$, hearing impairment $(\beta=-0.074,95 \%$ $C I=-0.090,-0.059)$, and dual sensory impairment $(\beta=-0.052,95 \% C I=-0.067,-0.036)$.

To further clarify associations between sensory impairment and cognitive function in different age groups, age was categorized into two groups: middle aged ( $\geq 45$ and $<60$ years old) and elderly ( $\geq 60$ years old; Table $4)$. In the elderly group, the multivariate-adjusted association between hearing impairment $(\beta=-0.072,95 \%$ $\mathrm{CI}=-0.095,-0.048)$ and dual impairment $(\beta=-0.040,95 \% \mathrm{CI}=-0.064,-0.017)$ and decline in memory persisted significantly compared to the reference group of no sensory impairment. A significant association was observed among subjects $\geq 60$ years old between vision impairment $(\beta=-0.043,95 \% \mathrm{CI}=-0.065,-0.021)$, hearing impairment $(\beta=-0.090,95 \% \mathrm{CI}=-0.112,-0.067)$, and dual impairment $(\beta=-0.062,95 \% \mathrm{CI}=-0.084$, $-0.040)$ and negative mental status. Vision impairment $(\beta=-0.033,95 \% \mathrm{CI}=-0.055,-0.011)$, hearing impairment $(\beta=-0.093,95 \% C I=-0.116,-0.071)$, and dual impairment $(\beta=-0.061,95 \% C I=-0.083,-0.039)$ were independently associated with decreased cognition for those $\geq 60$ years old. In the middle-aged group, memory was negatively associated with hearing impairment $(\beta=-0.033,95 \% \mathrm{CI}=-0.055,-0.011)$ and dual impairment $(\beta=-0.010,95 \% \mathrm{CI}=-0.032,-0.012)$. A negative association was found between mental status and vision impairment $(\beta=-0.019,95 \% \mathrm{CI}=-0.040,-0.002)$, hearing impairment $(\beta=-0.032,95 \% \mathrm{CI}=-0.053,-0.011)$, and dual impairment $(\beta=-0.029,95 \% \mathrm{CI}=-0.050,-0.008)$ among middle-aged people. There was also a significant 
Table 4. Associations between sensory impairment and cognitive function in middle-aged and elderly Chinese among age group*

\begin{tabular}{|c|c|c|c|c|}
\hline \multirow[b]{2}{*}{ VARIABLES } & \multicolumn{4}{|c|}{ SENSORY IMPAIRMENT } \\
\hline & $\begin{array}{l}\text { No sensory } \\
\text { impairment }\end{array}$ & Vision impairment & Hearing impairment & Dual sensory impairment \\
\hline \multicolumn{5}{|l|}{$\geq 60 \mathrm{y}:$} \\
\hline \multicolumn{5}{|l|}{ Memory: } \\
\hline Model 1 & Ref & $-0.020(-0.044,0.004)$ & $-0.088(-0.112,-0.063)$ & $-0.052(-0.077,-0.028)$ \\
\hline Model 2 & Ref & $-0.004(-0.027,0.019)$ & $-0.071(-0.095,-0.047)$ & $-0.039(-0.062,-0.016)$ \\
\hline Model 3 & Ref & $-0.005(-0.029,0.018)$ & $-0.072(-0.095,-0.048)$ & $-0.040(-0.064,-0.017)$ \\
\hline \multicolumn{5}{|c|}{ Mental status: } \\
\hline Model 1 & Ref & $-0.061(-0.084,-0.038)$ & $-0.112(-0.135,-0.088)$ & $-0.079(-0.103,-0.056)$ \\
\hline Model 2 & Ref & $-0.041(-0.064,-0.019)$ & $-0.089(-0.112,-0.067)$ & $-0.061(-0.083,-0.039)$ \\
\hline Model 3 & Ref & $-0.043(-0.065,-0.021)$ & $-0.090(-0.112,-0.067)$ & $-0.062(-0.084,-0.040)$ \\
\hline \multicolumn{5}{|l|}{ Cognition: } \\
\hline Model 1 & Ref & $-0.051(-0.075,-0.028)$ & $-0.115(-0.139,-0.092)$ & $-0.078(-0.101,-0.054)$ \\
\hline Model 2 & Ref & $-0.031(-0.053,-0.009)$ & $-0.093(-0.115,-0.070)$ & $-0.059(-0.081,-0.037)$ \\
\hline Model 3 & Ref & $-0.033(-0.055,-0.011)$ & $-0.093(-0.116,-0.071)$ & $-0.061(-0.083,-0.039)$ \\
\hline \multicolumn{5}{|c|}{$\geq 45$ and $<60$ y: } \\
\hline \multicolumn{5}{|l|}{ Memory } \\
\hline Model 1 & Ref & $-0.025(-0.047,-0.003)$ & $-0.045(-0.067,-0.023)$ & $-0.018(-0.040,0.05)$ \\
\hline Model 2 & Ref & $-0.013(-0.034,0.009)$ & $-0.033(-0.054,-0.011)$ & $-0.010(-0.032,0.016)$ \\
\hline Model 3 & Ref & $-0.013(-0.034,0.009)$ & $-0.033(-0.055,-0.011)$ & $-0.010(-0.032,-0.012)$ \\
\hline \multicolumn{5}{|c|}{ Mental status } \\
\hline Model 1 & Ref & $-0.038(-0.060,-0.016)$ & $-0.051(-0.073,-0.029)$ & $-0.041(-0.063,-0.019)$ \\
\hline Model 2 & Ref & $-0.019(-0.040,-0.002)$ & $-0.032(-0.053,-0.011)$ & $-0.029(-0.051,-0.008)$ \\
\hline Model 3 & Ref & $-0.019(-0.040,-0.002)$ & $-0.032(-0.053,-0.011)$ & $-0.029(-0.050,-0.008)$ \\
\hline \multicolumn{5}{|l|}{ Cognition } \\
\hline Model 1 & Ref & $-0.037(-0.060,-0.015)$ & $-0.055(-0.077,-0.033)$ & $-0.036(-0.058,-0.014)$ \\
\hline Model 2 & Ref & $-0.019(-0.040,-0.002)$ & $-0.036(-0.057,-0.015)$ & $-0.025(-0.046,-0.004)$ \\
\hline Model 3 & Ref & $-0.019(-0.040,-0.002)$ & $-0.037(-0.058,-0.016)$ & $-0.025(-0.046,-0.004)$ \\
\hline
\end{tabular}

* Model 1 adjusted for age and sex. Model 2 adjusted for covariates in model 1 plus marital status, residence, education, smoking status, and drinking status. Model 3 adjusted for covariates in model 2 plus, hypertension, dyslipidemia, and diabetes.

association between vision impairment $(\beta=-0.019,95 \% \mathrm{CI}=-0.040,-0.002)$, hearing impairment $(\beta=-0.037$, $95 \% \mathrm{CI}=-0.058,-0.016)$, and dual impairment $(\beta=-0.025,95 \% \mathrm{CI}=-0.046,-0.004)$ and a decline of cognition among middle-aged individuals.

\section{DISCUSSION}

With the aging of the global population, the increasing number of people suffering from cognitive dysfunction, doubling every 20 years, has become an imminent public crisis [20]. Most dementia patients are cared for by family members in the community, which bring their family caregivers great mental and physical pressure [21]. Thus, it is very important to explore and intervene factors related to cognitive function.

In the present study, we first analyzed and confirmed the negative association between hearing, vision, and dual sensory impairment and cognition impairment across middle-aged and elderly Chinese adults. Further adjustments for demographics, social economic factors, and lifestyle behavior lowered the association slightly, but it remained significant.

Memory, mental status, and cognitive function declined with the increase of age, drinking, and smoking status, which is consistent with previous studies [22-24]. However, these three cognitive-related indicators were positively associated with education and dyslipidemia. In previous studies evaluating dyslipidemia and cognitive functions, the findings were inconsistent, and mixed results were reported [25-27]. A recent study among 90 multiple sclerosis inpatients reported that a high level of triglycerides could be associated with an increased risk of cognitive impairment [25]. One possible reason for this is that while CHARLS participants are generalized to all middle-aged and older Chinese adults, this small study focused on multiple sclerosis patients. However, a 21-year follow-up study showed that a high midlife TC level comprised a risk factor for cognitive dysfunction in later life, whereas a low TC level was significantly associated with the risk of cognitive impairment late in life [27], which is consistent with our present study. 
Additionally, sensory impairment was significantly associated with worse memory, mental status, and cognition. Vision impairment was negatively associated with memory, but after adjusting for marital status, residence, education, smoking status, and drinking status, the association was not significant. However, visual impairment was negatively associated with mental status and cognition, even after controlling for demographics, social economic factors, lifestyle behavior, and metabolic measures. In a Korean study of adults who were 19 years of age or older, visually impaired people showed increased risk for poor mental status [28]. Furthermore, compared to healthy volunteers, glaucoma patients have worse mental states and are more likely to be associated with anxiety or depression; in glaucoma patients, the worse vision becomes, the worse mental status becomes [29]. These analyses support the results in our present study, specifically, the negative association between visual impairment and mental status. Similar to our findings, a NHANES and NHATS study reported that vision dysfunction was associated with poor cognitive function [30]. Recent studies have further suggested that there may be a causal relationship between worsening vision and future declining cognition [31]. As a result, retinal measurements of spectral-domain OCT were reported as one of the biomarkers of cognitive decline [32]. Although several studies have investigated the association between vision impairment and mental status and cognitive function, the influence of different age groups in the middle-aged and elderly is rarely mentioned, and extensive research using a large sample like CHARLS in China is not available. The present report found that there was a stronger negative association between mental status as well as cognition and vision impairment in the elderly compared to middle-aged people. Our study contributed further knowledge that visual impairment in the elderly has a greater association with cognition and mental status, which might impose a burden on normal daily life. Therefore, preventing, reducing, and correcting vision disorders early might lead to a decrease in cognition impairment among middle-aged and older adults.

Furthermore, hearing impairment was negatively associated with memory, mental status, and cognition, even after adjusting for age, sex, marital status, residence, education, smoking status, drinking status, hypertension, dyslipidemia, and diabetes. It is estimated that hearing loss, an independent risk factor for dementia, accounts for $9 \%$ of cases in middle-aged people [33]. There are some putative biological mechanisms for the relationship between hearing loss and dementia [34-36]. First, the pathology of the cerebral cortex that causes dementia also appears in the acoustic environment, including the cochlea and ascending auditory pathway [37-40]. Second, hearing loss causes an impoverished environment and negatively affects brain structure and function, leading to decreased cognitive reserves and decreased resilience to dementia [41-45]. Moreover, hearing impaired people utilize a portion of their cognitive resources to listen, which may result in the diminished availability of cognitive resources in the brain [35,46-48]. The occupied theory might also be a more agreeable explanation for age-related hearing loss. Additionally, hearing loss alters cortical activity, and there is an interaction between this altered activity and Alzheimer disease pathology, such as neurofibrillary changes associated with Tau pathology [36,49-51]. In our present study, there were stronger negative associations between hearing impairment and cognitive related indicators in the elderly compared to the middle-aged. Therefore, early hearing intervention for hearing impaired people may improve cognitive function to a certain extent. However, the improvement of cognitive function by using only hearing aids is limited and inconsistent [52-55], which may be due to the complex mechanism of age-related hearing loss. Further studies are thereby warranted to explore the cognitive benefits of multiple hearing interventions.

In the present study, dual sensory impairment was negatively associated with memory, mental status, and cognition, even after adjusting for other confounding factors. The association between dual sensory impairment and cognition is greater than that of visual impairment alone but not as great as that of hearing impairment alone. Few prior, but inconsistent, studies have reported the impact of dual sensory impairments on memory, mental status, and cognition. Participants with dual sensory impairment, rather than Alzheimer disease, were more likely to be diagnosed with dementia, but the average age of the participants was already 82.8 years old, and they were homecare clients [56]. In a longitudinal analysis, the population with dual vision and hearing impairment showed the greatest risk for cognitive function decline with the CIs overlapped with those for single impairment alone [57]. Based on existing research, it is difficult to say that dual sensory impairment confers greater risks for memory, emotional state, and cognition than hearing impairment alone.

Some limitations in our study should also be considered. First, as a cross-sectional analysis, our study cannot confirm the causal relationship between sensory impairment and cognitive impairment. Sensory impairment itself may be the result of cognitive impairment. Thus, we can only conclude that there is a significant negative association between sensory impairment and cognition. Second, the data on sensory impairment was self-reported. Although there are some differences between self-report and clinical data in evaluation, there are some studies that support the reliability of self-reported sensory disorders [58-60]. Therefore, the results involved in the study are still of great significance. 


\section{CONCLUSIONS}

In conclusion, the current study provides additional evidence that vision and hearing impairment are negatively associated with memory, mental status, and cognition for middle-aged and elderly Chinese adults. The results suggest that early interventions for vision and hearing disorders may improve the cognitive function of middle-aged and elderly people. Further research is needed to confirm our findings and help elderly people improve cognition.

Funding: This research was supported by the Shanghai Natural Science Foundation (19ZR1440900), Shanghai Pujiang
Program (2019PJD047), National Natural Science Foundation of China (81500714), National Natural Science Founda-
tion of China (81730026), National Key R\&D Program (2017YFA0105301), Multi-center Clinical Research Project from
Shanghai Jiao Tong University School of Medicine (DLY201813), Science and Technology Commission of Shanghai Mu-
nicipality (19495800700), Shanghai Hospital Development Center (SHDC2020CR2040B) and Shanghai Hospital Devel-
opment Center (SHDC2020CR5014).
Authorship contributions: XZ, MZ and XS conceived the cross-sectional study. YZ and KW were statistician and under-
took the secondary analysis. XB and JZ checked the statistical methods and analysis results. XZ, MZ and XS jointly draft-
ed the manuscript, which was contributed to by YZ and KW. All authors approved the final version of the manuscript.
Ethics approval: CHARLS was approved by the Ethical Review Committee at Peking University.
Competing interests: The authors completed the ICMJE Unified Competing Interest form (available upon request from
the corresponding author), and declare no conflicts of interest.

1 Centers for Disease Control and Prevention. Cognitive impairment: The impact on health in Iowa; 2011. Available: https:// www.cdc.gov/aging/pdf/cognitive_impairment/cogimp_ia_final.pdf. Accessed: 13 June 2016.

2 Zhang Y, Xu Y, Nie H, Lei T, Wu Y, Zhang L, et al. Prevalence of dementia and major dementia subtypes in the Chinese populations: a meta-analysis of dementia prevalence surveys, 1980-2010. J Clin Neurosci. 2012;19:1333-7. Medline:22682650 doi:10.1016/j.jocn.2012.01.029

3 Xiao S, Lewis M, Mellor D, McCabe M, Byrne L, Wang T, et al. The China longitudinal ageing study: overview of the demographic, psychosocial and cognitive data of the Shanghai sample. J Ment Health. 2016;25:131-6. Medline:26758526 doi:10. 3109/09638237.2015.1124385

4 Gold M, Lightfoot LA, Hnath-Chisolm T. Hearing loss in a memory disorders clinic. A specially vulnerable population. Arch Neurol. 1996;53:922-8. Medline:8815858 doi:10.1001/archneur.1996.00550090134019

5 Bowen M, Edgar DF, Hancock B, Haque S, Shah R, Buchanan S, et al. The Prevalence of Visual Impairment in People with Dementia (the PrOVIDe study): a cross-sectional study of people aged 60-89 years with dementia and qualitative exploration of individual, carer and professional perspectives. Southampton (UK): NIHR Journals Library; 2016.

6 Christensen JA, Sis J, Kulkarni AM, Chatterjee M. Effects of Age and Hearing Loss on the Recognition of Emotions in Speech. Ear Hear. 2019;40:1069-83. Medline:30614835 doi:10.1097/AUD.0000000000000694

7 Schubert CR, Cruickshanks KJ, Fischer ME, Pinto AA, Chen Y, Huang GH, et al. Sensorineural Impairments, Cardiovascular Risk Factors, and 10-Year Incidence of Cognitive Impairment and Decline in Midlife: The Beaver Dam Offspring Study. J Gerontol A Biol Sci Med Sci. 2019;74:1786-92. Medline:30629132 doi:10.1093/gerona/glz011

8 Schubert CR, Cruickshanks KJ, Fischer ME, Chen Y, Klein BEK, Klein R, et al. Sensory Impairments and Cognitive Function in Middle-Aged Adults. J Gerontol A Biol Sci Med Sci. 2017;72:1087-90. Medline:28535277 doi:10.1093/gerona/glx067

9 Armstrong RA. Visual Dysfunction in Parkinson's Disease. Int Rev Neurobiol. 2017;134:921-46. Medline:28805589 doi:10.1016/bs.irn.2017.04.007

10 Santangelo G, Trojano L, Vitale C, Ianniciello M, Amboni M, Grossi D, et al. A neuropsychological longitudinal study in Parkinson's patients with and without hallucinations. Mov Disord. 2007;22:2418-25. Medline:17894370 doi:10.1002/mds.21746

11 Swenor BK, Ramulu PY, Willis JR, Friedman D, Lin FR. The prevalence of concurrent hearing and vision impairment in the United States. JAMA Intern Med. 2013;173:312-3. Medline:23338042 doi:10.1001/jamainternmed.2013.1880

12 Brenowitz WD, Kaup AR, Lin FR, Yaffe K. Multiple Sensory Impairment Is Associated With Increased Risk of Dementia Among Black and White Older Adults. J Gerontol A Biol Sci Med Sci. 2019;74:890-6. Medline:30452551 doi:10.1093/gerona/gly264

13 Maharani A, Dawes P, Nazroo J, Tampubolon G, Pendleton N. Sense-Cog WP1 Group. Associations Between Self-Reported Sensory Impairment and Risk of Cognitive Decline and Impairment in the Health and Retirement Study Cohort. J Gerontol B Psychol Sci Soc Sci. 2020;75:1230-42. Medline:30977823 doi:10.1093/geronb/gbz043

14 Deardorff WJ, Liu PL, Sloane R, Van Houtven C, Pieper CF, Hastings SN, et al. Association of Sensory and Cognitive Impairment With Healthcare Utilization and Cost in Older Adults. J Am Geriatr Soc. 2019;67:1617-24. Medline:30924932 doi:10.1111/ jgs. 15891

15 Zhao Y, Hu Y, Smith JP, Strauss J, Yang G. Cohort profile: the China Health and Retirement Longitudinal Study (CHARLS). Int J Epidemiol. 2014;43:61-8. Medline:23243115 doi:10.1093/ije/dys203 
16 Beeri MS, Werner P, Davidson M, Schmidler J, Silverman J. Validation of the modified telephone interview for cognitive status (TICS-m) [in Hebrew]. Int J Geriatr Psychiatry. 2003;18:381-6. Medline:12766912 doi:10.1002/gps.840

17 Wei J, Yin X, Liu Q, Tan L, Jia C. Association between hypertension and cognitive function: A cross-sectional study in people over 45 years old in China. J Clin Hypertens (Greenwich). 2018;20:1575-83. Medline:30259624 doi:10.1111/jch.13393

18 Liu LS; Writing Group of 2010 Chinese Guidelines for the Management of Hypertension. 2010 Chinese guidelines for the management of hypertension. Zhonghua Xin Xue Guan Bing Za Zhi. 2011;39:579-615. Medline:22088239

19 Joint committee issued Chinese guideline for the management of dyslipidemia in adults. 2016 Chinese guideline for the management of dyslipidemia in adults. Zhonghua Xin Xue Guan Bing Za Zhi. 2016;44:833-53.

20 Cheng ST. Dementia Caregiver Burden: a Research Update and Critical Analysis. Curr Psychiatry Rep. 2017;19:64. Medline:28795386 doi:10.1007/s11920-017-0818-2

21 Pinquart M, Sörensen S. Differences between caregivers and noncaregivers in psychological health and physical health: a meta-analysis. Psychol Aging. 2003;18:250-67. Medline:12825775 doi:10.1037/0882-7974.18.2.250

$22 \mathrm{Hu}$ M, Yin H, Shu X, Jia Y, Leng M, Chen L. Multi-angles of smoking and mild cognitive impairment: is the association mediated by sleep duration? Neurol Sci. 2019;40:1019-27. Medline:30778881 doi:10.1007/s10072-019-03750-5

23 Teh WL, Abdin E, Vaingankar JA, Shafie S, Jeyagurunathan A, Yunjue Z, et al. Prevalence, Lifestyle Correlates, and Psychosocial Functioning Among Multi-Ethnic Older Adults with Mild Cognitive Impairment in Singapore: Preliminary Findings from a 10/66 Population Study. Yale J Biol Med. 2021;94:73-83. Medline:33795984

24 Koch M, Fitzpatrick AL, Rapp SR, Nahin RL, Williamson JD, Lopez OL, et al. Alcohol Consumption and Risk of Dementia and Cognitive Decline Among Older Adults With or Without Mild Cognitive Impairment. JAMA Netw Open. 2019;2:e1910319. Medline:31560382 doi:10.1001/jamanetworkopen.2019.10319

25 Andaloro A, Russo M, Pastura C, Sessa E, Calatozzo P, Maggio MG, et al. Is there a correlation between dyslipidemia and cognitive impairment in patients with multiple sclerosis? Int J Neurosci. 2020;1-6. Medline:32767908 doi:10.1080/00207454. 2020.1807980

26 Craft S. The role of metabolic disorders in Alzheimer disease and vascular dementia: two roads converged. Arch Neurol. 2009;66:300-5. Medline:19273747 doi:10.1001/archneurol.2009.27

27 Solomon A, Kåreholt I, Ngandu T, Winblad B, Nissinen A, Tuomilehto J, et al. Serum cholesterol changes after midlife and late-life cognition: twenty-one-year follow-up study. Neurology. 2007;68:751-6. Medline:17339582 doi:10.1212/01. wnl.0000256368.57375.b7

28 Cho GE, Lim DH, Baek M, Lee H, Kim SJ, Kang SW, et al. Visual Impairment of Korean Population: Prevalence and Impact on Mental Health. Invest Ophthalmol Vis Sci. 2015;56:4375-81. Medline:26176874

29 Jung KI, Park CK. Mental Health Status and Quality of Life in Undiagnosed Glaucoma Patients: A Nationwide Population-Based Study. Medicine (Baltimore). 2016;95:e3523. Medline:27175648 doi:10.1097/MD.0000000000003523

30 Chen SP, Bhattacharya J, Pershing S. Association of Vision Loss With Cognition in Older Adults. JAMA Ophthalmol. 2017;135:963-70. Medline:28817745 doi:10.1001/jamaophthalmol.2017.2838

31 Zheng DD, Swenor BK, Christ SL, West SK, Lam BL, Lee DJ. Longitudinal Associations Between Visual Impairment and Cognitive Functioning: The Salisbury Eye Evaluation Study. JAMA Ophthalmol. 2018;136:989-95. Medline:29955805 doi:10.1001/ jamaophthalmol.2018.2493

32 Chan VTT, Sun Z, Tang S, Chen LJ, Wong A, Tham CC, et al. Spectral-Domain OCT Measurements in Alzheimers Disease: A Systematic Review and Meta-analysis. Ophthalmology. 2019;126:497-510. Medline:30114417 doi:10.1016/j.ophtha.2018.08.009

33 Livingston G, Sommerlad A, Orgeta V, Costafreda SG, Huntley J, Ames D, et al. Dementia prevention, intervention, and care. Lancet. 2017;390:2673-734. Medline:28735855 doi:10.1016/S0140-6736(17)31363-6

34 Griffiths TD, Lad M, Kumar S, Holmes E, McMurray B, Maguire EA, et al. How Can Hearing Loss Cause Dementia? Neuron. 2020;108:401-12. Medline:32871106 doi:10.1016/j.neuron.2020.08.003

35 Bays PM, Husain M. Dynamic shifts of limited working memory resources in human vision. Science. 2008;321:851-4. Medline:18687968 doi:10.1126/science.1158023

36 Aronov D, Nevers R, Tank DW. Mapping of a non-spatial dimension by the hippocampal-entorhinal circuit. Nature. 2017;543:719-22. Medline:28358077 doi:10.1038/nature21692

37 O'Leary TP, Shin S, Fertan E, Dingle RN, Almuklass A, Gunn RK, et al. Reduced acoustic startle response and peripheral hearing loss in the 5xFAD mouse model of Alzheimer's disease. Genes Brain Behav. 2017;16:554-63. Medline:28133939 doi:10.1111/ gbb. 12370

38 Liu Y, Fang S, Liu LM, Zhu Y, Li CR, Chen K, et al. Hearing loss is an early biomarker in APP/PS1 Alzheimer's disease mice. Neurosci Lett. 2020;717:134705. Medline:31870800 doi:10.1016/j.neulet.2019.134705

39 Omata Y, Tharasegaran S, Lim YM, Yamasaki Y, Ishigaki Y, Tatsuno T, et al. Expression of amyloid- $\beta$ in mouse cochlear hair cells causes an early-onset auditory defect in high-frequency sound perception. Aging (Albany NY). 2016;8:427-39. Medline:26959388 doi:10.18632/aging. 100899

40 Kurata N, Schachern PA, Paparella MM, Cureoglu S. Histopathologic Evaluation of Vascular Findings in the Cochlea in Patients With Presbycusis. JAMA Otolaryngol Head Neck Surg. 2016;142:173-8. Medline:26747711 doi:10.1001/jamaoto.2015.3163

41 Häggström J, Hederstierna C, Rosenhall U, Östberg P, Idrizbegovic E. Prognostic Value of a Test of Central Auditory Function in Conversion from Mild Cognitive Impairment to Dementia. Audiol Neurootol. 2020;25:276-82. Medline:32388503 doi:10.1159/000506621

42 Holmes E, Griffiths TD. 'Normal' hearing thresholds and fundamental auditory grouping processes predict difficulties with speech-in-noise perception. Sci Rep. 2019;9:16771. Medline:31728002 doi:10.1038/s41598-019-53353-5 
43 Mamo SK, Reed NS, Sharrett AR, Albert MS, Coresh J, Mosley TH, et al. Relationship Between Domain-Specific Cognitive Function and Speech-in-Noise Performance in Older Adults: The Atherosclerosis Risk in Communities Hearing Pilot Study. Am J Audiol. 2019;28:1006-14. Medline:31825642 doi:10.1044/2019_AJA-19-00043

44 Pronk M, Lissenberg-Witte BI, van der Aa HPA, Comijs HC, Smits C, Lemke U, et al. Longitudinal Relationships Between Decline in Speech-in-Noise Recognition Ability and Cognitive Functioning: The Longitudinal Aging Study Amsterdam. J Speech Lang Hear Res. 2019;62:1167-87. Medline:31026198 doi:10.1044/2018_JSLHR-H-ASCC7-18-0120

45 Neuschwander P, Hänggi J, Zekveld AA, Meyer M. Cortical thickness of left Heschl's gyrus correlates with hearing acuity in adults - A surface-based morphometry study. Hear Res. 2019;384:107823. Medline:31678891 doi:10.1016/j.heares.2019.107823

46 Uchida Y, Sugiura S, Nishita Y, Saji N, Sone M, Ueda H. Age-related hearing loss and cognitive decline - The potential mechanisms linking the two. Auris Nasus Larynx. 2019;46:1-9. Medline:30177417 doi:10.1016/j.anl.2018.08.010

47 Pichora-Fuller MK, Kramer SE, Eckert MA, Edwards B, Hornsby BW, Humes LE, et al. Hearing Impairment and Cognitive Energy: The Framework for Understanding Effortful Listening (FUEL). Ear Hear. 2016;37 Suppl 1:5S-27S. Medline:27355771 doi:10.1097/AUD.0000000000000312

48 Kumar S, Joseph S, Pearson B, Teki S, Fox ZV, Griffiths TD, et al. Resource allocation and prioritization in auditory working memory. Cogn Neurosci. 2013;4:12-20. Medline:23486527 doi:10.1080/17588928.2012.716416

49 Ahmed MS, Priestley JB, Castro A, Stefanini F, Solis Canales AS, Balough EM, et al. Hippocampal Network Reorganization Underlies the Formation of a Temporal Association Memory. Neuron. 2020;107:283-291.e6. Medline:32392472 doi:10.1016/j. neuron.2020.04.013

50 Kumar S, Gander PE, Berger JI, Billig AJ, Nourski KV, Oya H, et al. Oscillatory correlates of auditory working memory examined with human electrocorticography. Neuropsychologia. 2021;150:107691. Medline:33227284 doi:10.1016/j.neuropsychologia.2020.107691

51 Martin CB, Douglas D, Newsome RN, Man LL, Barense MD. Integrative and distinctive coding of visual and conceptual object features in the ventral visual stream. eLife. 2018;7:e31873. Medline:29393853 doi:10.7554/eLife.31873

52 Deal JA, Albert MS, Arnold M, Bangdiwala SI, Chisolm T, Davis S, et al. A randomized feasibility pilot trial of hearing treatment for reducing cognitive decline: Results from the Aging and Cognitive Health Evaluation in Elders Pilot Study. Alzheimers Dement (N Y). 2017;3:410-5. Medline:29067347 doi:10.1016/j.trci.2017.06.003

53 Nguyen MF, Bonnefoy M, Adrait A, Gueugnon M, Petitot C, Collet L, et al. Efficacy of Hearing Aids on the Cognitive Status of Patients with Alzheimer's Disease and Hearing Loss: A Multicenter Controlled Randomized Trial. J Alzheimers Dis. 2017;58:12337. Medline:28387664 doi:10.3233/JAD-160793

54 Mosnier I, Bebear JP, Marx M, Fraysse B, Truy E, Lina-Granade G, et al. Improvement of cognitive function after cochlear implantation in elderly patients. JAMA Otolaryngol Head Neck Surg. 2015;141:442-50. Medline:25763680 doi:10.1001/jamaoto.2015.129

55 Dawes P, Emsley R, Cruickshanks KJ, Moore DR, Fortnum H, Edmondson-Jones M, et al. Hearing loss and cognition: the role of hearing AIDS, social isolation and depression. PLoS One. 2015;10:e0119616. Medline:25760329 doi:10.1371/journal.pone.0119616

56 Davidson JGS, Guthrie DM. Older Adults With a Combination of Vision and Hearing Impairment Experience Higher Rates of Cognitive Impairment, Functional Dependence, and Worse Outcomes Across a Set of Quality Indicators. J Aging Health. 2019;31:85-108. Medline:28805100 doi:10.1177/0898264317723407

57 Lin MY, Gutierrez PR, Stone KL, Yaffe K, Ensrud KE, Fink HA, et al. Vision impairment and combined vision and hearing impairment predict cognitive and functional decline in older women. J Am Geriatr Soc. 2004;52:1996-2002. Medline:15571533 doi:10.1111/j.1532-5415.2004.52554.x

58 Reuben DB, Walsh K, Moore AA, Damesyn M, Greendale GA. Hearing loss in community-dwelling older persons: national prevalence data and identification using simple questions. J Am Geriatr Soc. 1998;46:1008-11. Medline:9706892 doi:10.1111/j.1532-5415.1998.tb02758.x

59 Rudberg MA, Furner SE, Dunn JE, Cassel CK. The relationship of visual and hearing impairments to disability: an analysis using the longitudinal study of aging. J Gerontol. 1993;48:M261-5. Medline:8227996 doi:10.1093/geronj/48.6.M261

60 Wallhagen MI, Strawbridge WJ, Shema SJ, Kurata J, Kaplan GA. Comparative impact of hearing and vision impairment on subsequent functioning. J Am Geriatr Soc. 2001;49:1086-92. Medline:11555071 doi:10.1046/j.1532-5415.2001.49213.x 